\title{
Long term outcome of patients with postinfarction left ventricular pseudoaneurysm
}

\author{
R Moreno, E Gordillo, J Zamorano, C Almeria, J C Garcia-Rubira, A Fernandez-Ortiz, \\ C Macaya
}

Heart 2003;89:1144-1146

See end of article for authors' affiliations

Correspondence to:

Dr Raúl Moreno, Instituto

Cardiovascular, Hospital

Clínico San Carlos; Martín

Lagos, s/n, Madrid, Spain;

raulmorenog@terra.es

Accepted 17 April 2003
Background: It is debatable whether surgical repair is routinely indicated in asymptomatic patients with left ventricular pseudoaneurysms.

Objective: To evaluate the long term outcome of patients with pseudoaneurysm after myocardial infarction, focusing on those treated conservatively.

Methods: 10 patients with postinfarction left ventricular pseudoaneurysm were followed up over a mean (SD) period of $3.8(5.2)$ years.

Results: In those treated conservatively $(n=9)$, cumulative survival was $88.9(10.5) \%$ and 74.1 (16.1)\% at one and four years, respectively. The probability of being free of cardiac death was 88.9 (10.5)\% at both one and four years. No patient had complete fatal heart rupture during follow up. Three patients suffered ischaemic stroke (at 1, 11, and 62 months). The cumulative incidence of ischaemic stroke was $10 \%$ at one year and $32.5 \%$ at four years.

Conclusions: Long term outcome of patients with postinfarction left ventricular pseudoaneurysm is relatively benign, with a very low risk (none in this series) of fatal rupture. Taking into consideration the relatively high risk of stroke, chronic anticoagulant treatment could be considered. eft eft ventricular pseudoaneurysm is a very rare complication following acute myocardial infarction, which results from a free wall rupture in which immediate haemopericardium and cardiac tamponade is not produced. ${ }^{12}$ Owing to the possibility of subsequent complete rupture and death, irrespective of chronicity, ${ }^{3}$ surgical repair is usually recommended when a left ventricular pseudoaneurysm is detected. ${ }^{4-6}$ However, the risk of fatal rupture seems to be low in patients treated conservatively. ${ }^{7}$

Our aim in this study was to evaluate the long term outcome of postinfarction left ventricular pseudoaneurysm. We followed up 10 patients diagnosed with this condition.

\section{METHODS \\ Study population}

The study population comprised 10 patients diagnosed with left ventricular pseudoaneurysm at our institution. The diagnosis was mainly based on echocardiographic data, the main features being the presence of an echo-free space adjacent to and in communication with the left ventricular cavity, with a diameter that was larger than the communicating orifice. ${ }^{89}$ Flow into and out of the pseudoaneurysm cavity was detected on colour flow imaging and pulsed wave Doppler in all patients. Contrast agents were used in seven patients to achieve clearer visualisation of blood flow from the left ventricle into the pseudoaneurysm cavity. ${ }^{10}$ Magnetic resonance imaging or contrast ventriculography were undertaken in cases where the diagnosis of pseudoaneurysm could not be definitively established by echocardiography. ${ }^{11}$

\section{Follow up and statistical analysis}

Patients were followed up for a mean (SD) period of 3.8 (5.2) years after the myocardial infarction (range $0.2-15.3$ years). Continuous data are expressed as mean (SD), and qualitative variables as proportions (percentages). Cumulative survival rates were studied using Kaplan-Meier curves.

\section{RESULTS}

\section{Baseline characteristics}

Table 1 shows the clinical characteristics of the patient population. Of the 10 patients, seven were male and three female. Their mean age was 63 (12) years (range 48-85 years). Infarct location was inferior in six cases, anterior in three, and both anterior and inferior in one. Reperfusion strategies were used in three patients (all received thrombolysis). Coronary angiography was done in eight patients, of whom four $(50 \%)$ had multivessel disease, and five (63\%) had a completely occluded infarct related artery. The mean size of the communicating orifice was 9.8 (6.9) $\mathrm{mm}$ (range 3-21 mm), and the inner diameter of the left ventricular pseudoaneurysm was 29.1 (14.4) mm (range 11-51 mm).

\section{Clinical presentation and treatment given}

A pseudoaneurysm was diagnosed during the initial hospital admission in six cases. In three of these an echocardiographic study was done to rule out mechanical complications in the presence of haemodynamic impairment during the acute phase; in the other three the pseudoaneurysm was an incidental finding during routine echocardiographic studies. The diagnosis of left ventricular pseudoaneurysm was established after discharge in the remaining four patients, clinical presentation being ischaemic stroke in three and heart failure in one.

The pseudoaneurysm was surgically repaired in only one patient. The remaining nine were managed conservatively because of advanced age, left ventricular dysfunction, recent ischaemic stroke, or co-morbidity.

\section{Long term follow up}

Follow up was achieved in all patients. Only two deaths occurred (both in patients managed conservatively)-one from progressive heart failure and one from pancreatic carcinoma, at two and 13 months, respectively. Figure 1 shows the cumulative survival rate and the probability of being free of cardiac death. Cumulative survival rate was $90(9) \%$ at one year and $75(16) \%$ at four years. Cumulative rate of cardiac 
Table 1 Clinical details of the patients

\begin{tabular}{|c|c|c|c|c|c|c|c|}
\hline Patient & $\begin{array}{l}\text { Age } \\
\text { (years) }\end{array}$ & Sex & $\begin{array}{l}\text { Time since } \\
\text { AMI (months) }\end{array}$ & Surgery & WMSI & Death & Stroke \\
\hline 1 & 48 & $\mathrm{~F}$ & 1 & Yes & 1.44 & No & No \\
\hline 2 & 59 & $\mathrm{~F}$ & 125 & No & 1.67 & No & No \\
\hline 3 & 85 & $\mathrm{~F}$ & 1 & No & 1.44 & Yes & Yes \\
\hline 4 & 68 & $M$ & 62 & No & 1.44 & No & Yes \\
\hline 5 & 46 & $M$ & 2 & No & 2.11 & No & No \\
\hline 6 & 72 & $M$ & 1 & No & 1.44 & No & No \\
\hline 7 & 51 & $M$ & 1 & No & 2.17 & No & Yes \\
\hline 8 & 63 & $M$ & 130 & No & 2.00 & No & No \\
\hline 9 & 63 & $M$ & 1 & No & 2.56 & No & No \\
\hline 10 & 76 & $M$ & 1 & No & 1.89 & Yes* & No \\
\hline
\end{tabular}

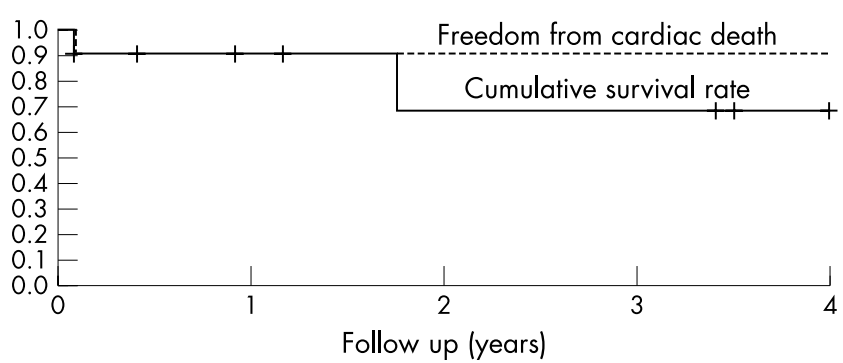

Figure 1 Kaplan-Meier cumulative survival curve and probability of being free from cardiac death.

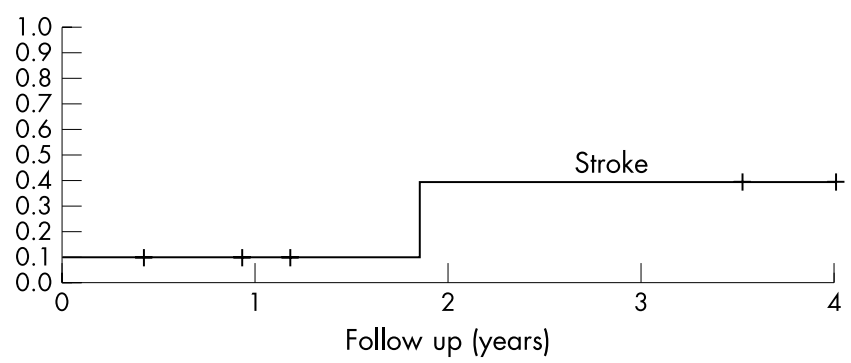

Figure 2 Cumulative incidence of ischaemic stroke.

death at four years was $10 \%$. Three patients had an ischaemic stroke (at 1, 11, and 62 months). The cumulative incidence of ischaemic stroke was $10 \%$ at one year and $32.5 \%$ at four years (fig 2). Among patients treated conservatively $(\mathrm{n}=9)$, cumulative survival was $88.9(10.5) \%$ and $74.1(16.1) \%$ at one and four years, respectively; the probability of being free of cardiac death was 88.9 (10.5)\% at both one and four years.

\section{DISCUSSION}

Left ventricular pseudoaneurysm is a very rare complication of acute myocardial infarction in which a free wall rupture is contained by overlying adherent pericardium. ${ }^{12}$ As reported previously, pseudoaneurysms may lead to fatal rupture a long time after the myocardial infarction, ${ }^{3}$ and because of this most clinicians recommend surgical repair as soon as possible when the diagnosis is established, irrespective of chronicity. ${ }^{4-6}$ However, two variables have to be taken into account when deciding whether routine surgical repair of a pseudoaneurysm should be undertaken: postoperative mortality following the procedure, and the risk of fatal rupture with conservative treatment. Postoperative mortality after surgical repair of a left ventricular pseudoaneurysm ranges from $13-29 \% .{ }^{12-14}$ However, most cardiologists consider this relatively high mortality acceptable because of the risk of fatal rupture. ${ }^{12}$

The possibility of fatal rupture irrespective of chronicity is well known in left ventricular pseudoaneurysm. ${ }^{3}$ On the other hand, the outcome of patients with this condition treated conservatively has been assumed to be poor, with a mortality of around $50 \%$ at two years in one series. ${ }^{6}$ However, data on the long term prognosis with conservative management are relatively sparse, and death from fatal rupture seems to be uncommon. In a study by Yeo and colleagues, ${ }^{4}$ five of six patients with left ventricular pseudoaneurysm treated conservatively died after a mean follow up of 3.2 years. However, three of these deaths were non-cardiac, and in neither of the other two cases was death caused by rupture of the aneurysm. In a recent review, Natarajan and colleagues concluded that medical treatment of chronic pseudoaneurysm is not associated with an increased risk of cardiac rupture.13

In our study, only one young female patient with relatively preserved left ventricular systolic function was operated on. The outcome in our conservatively treated patients was relatively good, with a mortality of $26 \%$, and an incidence of cardiac death of $11 \%$ at four years. Importantly, no patient suffered fatal cardiac rupture. Our results, therefore, are in agreement with other studies in which the risk of suffering complete fatal rupture is very low, supporting a conservative management policy unless the surgical risk is considered low on account of young age, good left ventricular ejection fraction, and lack of co-morbidity. On the other hand, the relatively high incidence of ischaemic stroke $132.5 \%$ at four years) suggests that chronic anticoagulation should be considered in these patients. In one study, $13 \%$ of the patients with a left ventricular pseudoaneurysm had systemic embolism as the clinical presentation. ${ }^{13}$

The clinical and angiographic characteristics of our study population do not differ from those of previous series of patients with left ventricular pseudoaneurysm or other mechanical complications. ${ }^{6}{ }^{13-15}$ Most patients did not receive reperfusion treatment during the acute phase of the myocardial infarct, in accordance with the view that successful mechanical reperfusion reduces the risk of mechanical complications. ${ }^{16}$

\section{Conclusions}

The long term outcome of patients with postinfarction left ventricular pseudoaneurysm appears relatively benign, with a very low risk (no risk in our series) of fatal rupture. This has to take into consideration when deciding whether or not surgical repair is indicated in these patients.

\section{Authors' affiliations}

R Moreno, E Gordillo, J Zamorano, C Almeria, J C Garcia-Rubira, A Fernandez-Ortiz, C Macaya, Instituto Cardiovascular, Hospital Clínico San Carlos, Madrid, Spain

\section{REFERENCES}

1 Roberts WC, Morrow AG. Pseudoaneurysm of the left ventricle: an unusual sequel of myocardial infarction and rupture of the heart. Am J Med 1967;43:639-44. 
2 Chesler E, Korns ME, Semba T, et al. False aneurysms of the left ventricle following myocardial infarction. Am J Cardiol 1969;23:76-82.

3 Vlodaver Z, Coe JI, Edwards JE. True and false left ventricular aneurysms: propensity for the latter to rupture. Circulation 1975;51:567-72.

4 Yeo TC, Malouf JF, Reeder GS, et al. Clinical characteristics and outcome in postinfarction pseudoaneurysm. Am J Cardiol 1999:84:592-5

5 Gueron $M$, Wanderman KL, Hirsch M, et al. Pseudoaneurysm of the left ventricle after myocardial infarction: a curable form of myocardial rupture. Thorac Cardiovasc Surg 1975;69:736-42.

6 Csapo K, Voith L, Szuk T, et al. Postinfarction left ventricular pseudoaneurysm. Clin Cardiol 1997;20:898-903.

7 Gatewood RP, Nanda NC. Differentiation of left ventricular pseudoaneurysm from true aneurysm with two-dimensional echocardiography. Am J Cardiol 1980;46:869-78.

8 Roelandt JR, Sutherland GR, Yoshida K, et al. Improved diagnosis and characterization of left ventricular pseudoaneurysm by Doppler color flow imaging. J Am Coll Cardiol 1988;3:807-1 1.

9 Moreno R, Zamorano J, Almería C, et al. Usefulness of contrast agents in the diagnosis of left ventricular pseudoaneurysm after acute myocardial infarction. Eur J Echocardiogr 2002;3:111-16.
10 Candell-Riera J, Rius A, Aguadé S, et al. [Diagnóstico de pseudoaneurismas ventriculares. El papel complementario de la ecocardiografía, la ventriculografía isotópica y la ventriculografía de contraste.] Rev Esp Cardiol 1993;46:225-34.

11 Pretre $\mathbf{R}$, Linka A, Jenni $R$, et al. Surgical treatment of acquired left ventricular pseudoaneurysms. Ann Thorac Surg 2000;70:553-7.

12 Komeda M, David TE. Surgical treatment of postinfarction false aneurysm of the left ventricle. J Thorac Cardiovasc Surg 1993; 106:1 189-91

13 Natarajan MK, Salerno TA, Burke B, et al. Chronic false aneurysms of the left ventricle: management revisited. Can J Cardiol 1994;10:927-31.

14 Figueras $\mathrm{J}$, Cortadellas J, Domingo $\mathrm{E}$, et al. Survival following self-limited left ventricular free wall rupture during myocardial infarction. Management differences between patients with or without pseudoaneurysm formation. Int J Cardiol 2001;79:103-11.

15 Moreno R, López de Sá E, López-Sendón JL, et al. Frequency of ventricular free wall rupture in patients with acute myocardia infarction treated with primary angioplasty. Am J Cardiol 2000;85:757-60

16 Moreno R, López-Sendón JL, García E, et al. Primary angioplasty reduces the risk of left ventricular free wall rupture compared with thrombolysis in patients with acute myocardial infarction. J Am Coll Cardiol 2002;39:598-603

\section{IMAGES IN CARDIOLOGY}

\section{Multi-vessel dissections in Marfan syndrome demonstrated by multislice computed tomography}

A 36 year old man with Marfan syndrome presented at our hospital because of back pain. He had aortic dissection in the ascending aorta with aortic valve regurgitation, and received the Bentall operation in which the ascending aorta was replaced by an artificial vessel with artificial aortic valves. To evaluate the lumen of the aorta and main branch, ECG gated enhanced multislice computed tomography (CT) (Light Speed Ultra, General Electric, Milwaukee, Wisconsin, USA) was performed with a $1.25 \mathrm{~mm}$ slice thickness and 3.25 helical pitch. Following intravenous injection of $100 \mathrm{ml}$ of iodinated contrast material $(350 \mathrm{mgI} / \mathrm{ml})$, CT scanning was performed and volume data were transferred to a workstation (M900, Zio, Tokyo, Japan). The multiple intimal flaps (arrowheads, upper panel, A, B) suggested a huge complex aortic dissection covering a wide range from the native aortic arch to the entire range of the descending thoracic aorta, which continued to the left common carotid artery (CCA). There were also dissections in the right and left CCAs and right and left subclavian arteries in which all true and false lumens were enhanced by contrast material (middle panel, A, B). Observing both CCAs in three dimensional volume rendering images (lower panel), there was re-entry in the proximal portion of the left internal carotid artery (ICA) and confluence of the true and false lumen with good enhancement. Also, there was re-entry at the distal portion of the right CCA and confluence of the true and false lumen with good enhancement, showing separation into the right external carotid artery (ECA) and ICA.

N Funabashi

$\mathrm{K}$ Ito

I Komuro

komuro-tky@umin.ac.jp
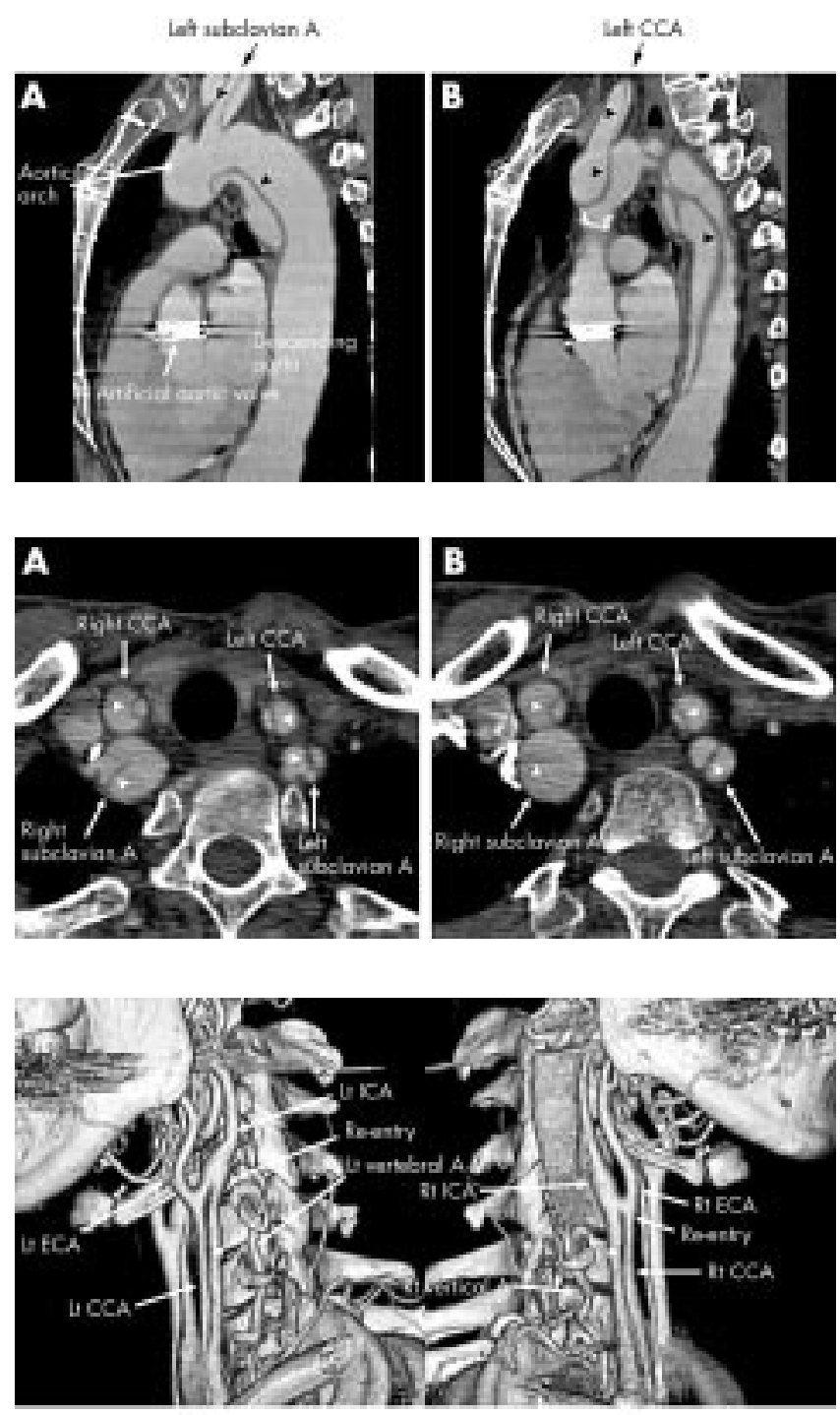

$B$ 